Challenges of Developing a New Engineering Drawings Course for Civil Engineers

Mr. Bradley James Schmid, University of Saskatchewan

Brad Schmid is an assistant professor in Civil, Geological, and Environmental Engineering at the University of Saskatchewan. 


\title{
Challenges of Developing a New Engineering Drawings Course for Civil Engineering
}

\begin{abstract}
The landscape of engineering graphics and design have changed substantially in the last twenty to thirty years, yet in many ways the courses and curriculum have often not adapted sufficiently to the changes in technology, design process, or integration of graphics and design through computer applications. This paper presents the considerations undertaken in the design of this course and the impact of this course on other courses in the program.
\end{abstract}

Having the opportunity to design a completely new course with a focus on spatial analysis and engineering drawings for civil engineers has provided the opportunity to review common educational offerings in other civil engineering programs and textbooks from major publishers on engineering graphics. While there was some modernization in many University offerings, the textbook resources were found to either be developed specifically for learning a software product or were a modestly updated version of traditional drafting textbooks.

The challenge we chose was to develop a course that links aspects of traditional drafting with modern computer aided design (CAD) and geographic information systems (GIS) that would also introduce areas of design in civil engineering that would be used and built on in other courses.

Many civil engineering, and indeed engineering programs in general, use AutoCAD in their introductory courses. In our case we chose to introduce basic aspects of computer aided design using AutoCAD but then moved to more sophisticated design software; AutoCAD Civil3D. This choice was overwhelming to some students in our first iteration but supports for student learning in subsequent years significantly improved the student experience. Civil3D can also perform aspects of GIS analysis and provides a valuable learning experience for students, though other software is typically used in practice for GIS applications.

The specific course that was developed is given in the first term of second year and introduces design aspects for roadways, land development, water resources, earthworks, and storm water and sanitary sewer systems. This introduction to design is leveraged in several other courses in the program which had historically not had the resources and schedule to be able to include CAD, having to rely mainly on hand calculations for analysis even though the use CAD is almost always used in practice.

\section{Background and Need}

A new course for Civil and Geological Engineering students has recently been introduced. Prior to 1998, all first-year engineering students were required to complete a single semester course in Graphics and Descriptive Geometry that taught traditional drafting using pencil and paper in a formal classroom with drafting tables. This course was part of a common first year program at that all engineering students follow prior to entering their chosen department for their second year of studies. The first-year program was redesigned to include the basics of drawing and sketching but did not cover drafting to the extent previously covered and required individual 
programs (eg. Civil, Mechanical, Chemical, or Electrical Engineering) to determine for their individual programs any further Engineering Graphics requirements.

Within the Civil, Geological and Environmental programs, the decision was taken to require students to complete an introductory AutoCAD course[1] at a neighboring technical institution as part of their program. This was a reasonable measure for the interim but for the longer term, a more integrated offering was desired. A replacement course has now been developed and was first offered in September 2016.

The first year course taken by all engineering students in the college, and a prerequisite for this course, includes the following topics: isometric and orthographic drawings and translations back and forth between the two, freehand sketching, section and auxiliary views, scaling and dimensioning, lettering, titles, borders, and interpretation of disciplinary-specific drawings.

Several follow-on courses were identified where the use of CAD software would be beneficial including second-year design, transportation, municipal, geotechnical, structural, water resources, fourth year design, and surveying courses. While the potential for other classes to benefit from the introduction of this course exists, it was obvious that the needs of all specialties could not be met with a single course and that the choice of software would also be a limitation.

In recent years, it has also become more common for high school students in Canada to enter university with some experience using CAD software, typically AutoCAD or Inventor. The opportunities are offered in high schools and there are provincial and national competitions in the use of CAD through Skills Canada[2]. This causes a significant difference in the incoming student's ability and self confidence related to this course.

\section{Teaching and Learning Philosophy}

Central to the teaching and learning philosophy of this course was that a significant component of the course would be learned and experienced through computer laboratory sessions. With this in mind, the typically 12-week duration course was set to have 1.5 hours per week of lectures and 3 hours per week of computer lab sessions. The lectures would be undertaken in a single section and would typically have an enrolment of approximately 100 students. Each of the labs would have a maximum size of 45 students, typically requiring three lab sections, which would be run in two 1.5-hour sessions per week.

The lecture component of the course was used to introduce materials to support the lab activities as well as including concepts related to engineering drawings that were of importance to civil engineers. These lectures included the following topics: computer aided design, review of drafting and CAD standards, mapping and site maps, geographic information systems, coordinate systems and coordinate transformations, types of data (eg. raster and vector), use of CAD in land development, road design in CAD, volume calculations, building information modelling (BIM), and pipe network design in CAD for water distribution and collection systems.

In the labs, the use of CAD software was demonstrated, and the students were given assignments to complete. The philosophy in the labs was to demonstrate how the software worked and how you should work with the software to complete the assignment. The labs did not provide a rigorous step-by-step instruction typical of what you may observe at a technology school (i.e. 
'click here then type this' type of instructions). Instead the students were shown how to find the software tools that would do the functions they required and learn to understand what the software is doing or asking for. This type of instruction was initially frustrating to students but was overcome with class supports as described in detail in a companion paper[3].

\section{Software Considerations}

The choice of software was an important decision to make early in the planning process. There are many options available and many alternatives could have resulted in acceptable learning outcomes for students. The most applicable graphics software for our civil engineering program consisted of AutoCAD, Civil 3D, and Revit. Other programs such as SketchUp or Civil design software from developers such as Bentley or MicroStation could have been used in the delivery of the course.

The decision was made to use AutoCAD and Civil 3D in the course because the software is widely used in civil engineering, the software is available to students free of charge, and there are many design features available in Civil 3D. These features include land development tools, road and rail design tools, earthworks tools, piping network design tools, and it has some geographic information systems tools. This capability allows a large range of practical civil engineering designs to be undertaken in the software.

Many of our student's primary interest is in structural engineering, which would have made it desirable to include Revit in the course. Additionally, many students would benefit from using geographic information system (GIS) software such as ArcGIS in the subject areas of hydrology and water resources. It is ultimately not possible to cover the wide range of CAD and GIS software in a single course and an attempt to do so would place too much emphasis on learning particular pieces of software and not the process of designing and creating drawings in the software.

\section{Textbooks}

A review of textbooks was undertaken to determine if there were suitable resources already available for this course. This review of resources found two main types of resources available; textbooks that contained the traditional engineering graphics materials that were used when teaching a traditional drafting course and books that provide instruction how to use specific CAD software such as Civil 3D. Both types of resources are valuable but neither really cover the desired content of our course, which could be considered a blend of civil engineering design, engineering graphics, geography, and geodesy.

As a result, no textbook was assigned for the course. Course notes are provided for the course lectures while video resources and some notes are given for the lab component of the course.

\section{Classroom Technology}

Classroom technology has been widely used in this course and that use is discussed in a companion paper[3] that discusses the effectiveness of classroom technology to this course offering. Technology that has been used in the course included the learning management system BlackBoard, the audience response system TopHat, the video recording platform Panopto, video 
tutorials from Lynda.com, and the use of Webex video conferencing during computer laboratories. These technologies were all available to students at our university at no extra charge because the University had procured campus wide licenses from each provider.

\section{Benefit to Follow-on Courses}

The relationship between the developed course and other course in the civil engineering program are shown in Figure 1. Engineering Design is a prerequisite to the developed course while the developed course is a prerequisite to the Design Project Course in second year.

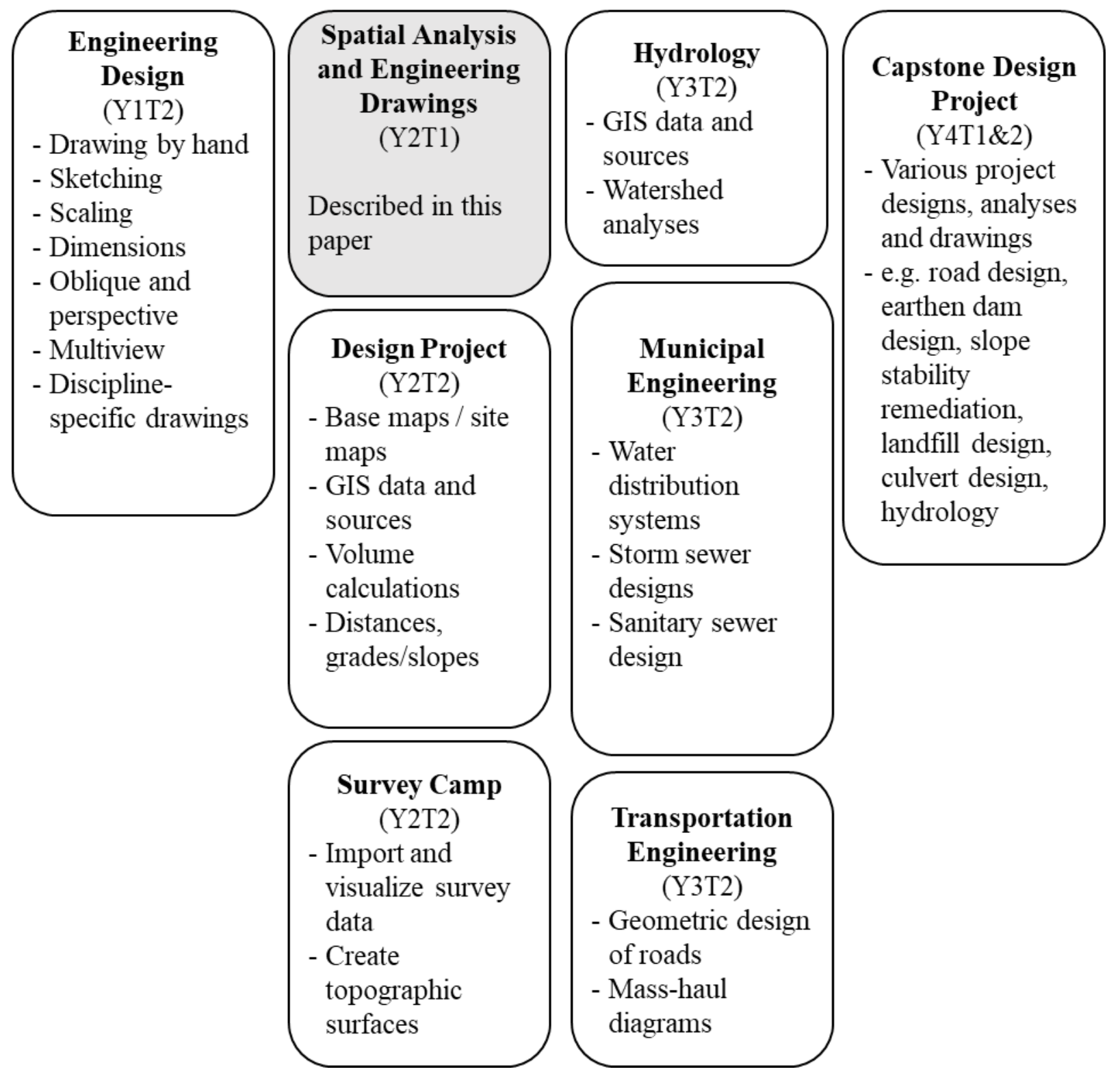

Figure 1 Relationship of the new course (Spatial Analysis and Engineering Drawings) to other courses in the civil engineering program. Values in parentheses indicate the year and term the course is offered. Bulleted lists describe the aspects related to content from the developed course. 
Surveys were taken in the second-year civil engineering design course that follows in the semester after this course. Measurements of student confidence in producing site maps and using computer software to describe the spatial characteristics such as size, slope, and proximity to other objects were measure before the new drawings course was introduced and following the implementation of the course. No statistically significant changes were observed in these measurements. Instructors of this follow-on course noted that there was some improvement in student's ability to produce site maps and drawings, though the improvement was not large.

These survey results displayed in Figures 2 through 4 may reflect some of the difficulties encountered in the first offering of the course including the need for additional student supports for the demands of this new course.

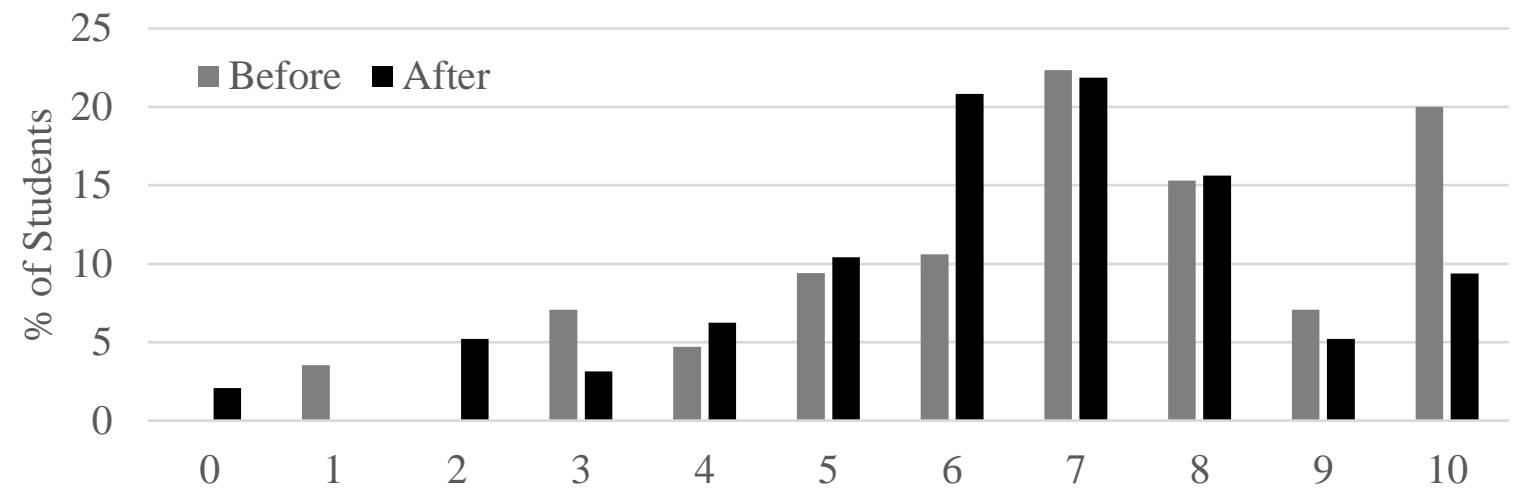

Figure 2 Student confidence that they could create a map of a project site. 0 indicates not confident while 10 indicates very confident. Before indicates survey responses taken 1 year before the course was introduced while After indicates measurements taken after the first offering of the course.

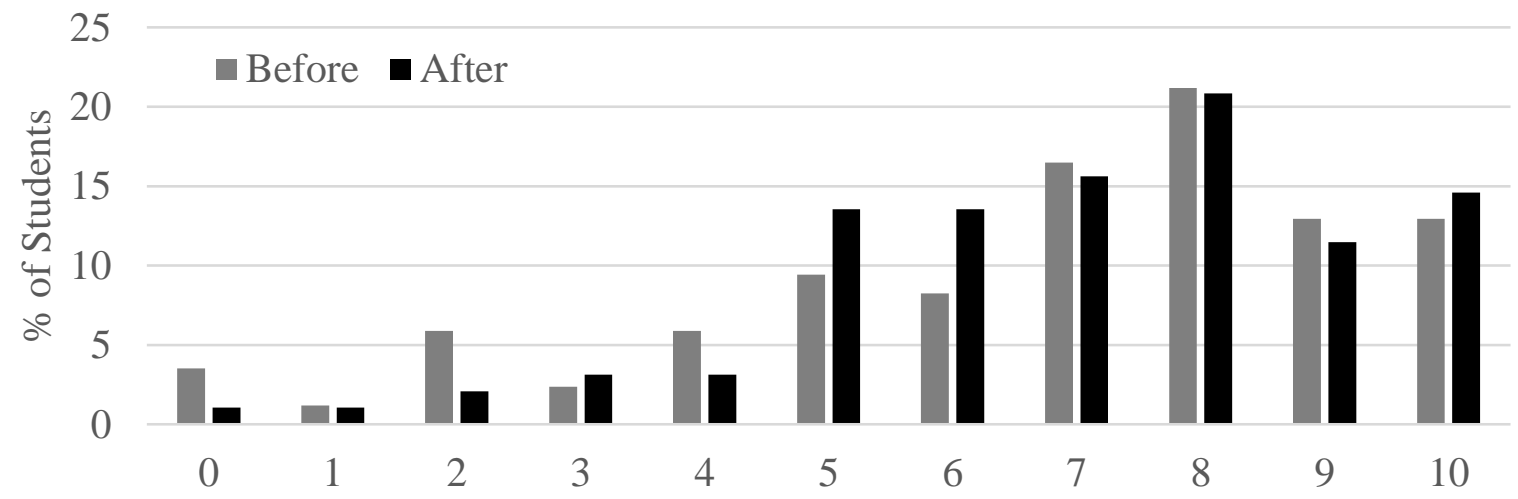

Figure 3 Student confidence that they could create a 3D drawing of an object or design. 0 indicates not confident while 10 indicates very confident. Before indicates survey responses taken the year before the course was introduced while After indicates measurements taken after the first offering of the course. 


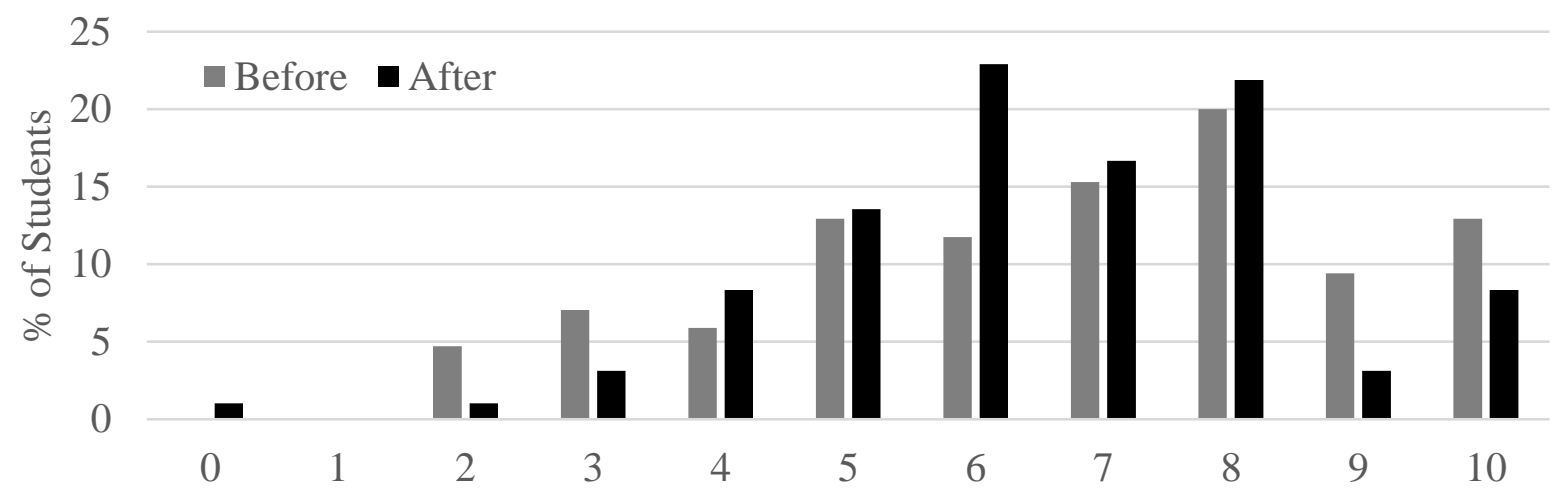

Figure 4 Student confidence that they could use computer tools to describe the spatial characteristics of a site or object. 0 indicates not confident while 10 indicates very confident. Before indicates survey responses taken the year before the course was introduced while After indicates measurements taken after the first offering of the course.

In a follow-on transportation course, a road design lab assignment that had historically been completed using manual drawing methods is now being completed using Civil 3D with little instruction in Civil 3D required for students to complete the assignment.

Several student teams in the fourth-year capstone design course are making use CAD extensively in the projects for the creation of design drawings, calculations such as cut and fill and for report and presentation graphics. In some cases, these teams have learned additional software such as Revit to complete structural drawings entirely on their own with confidence gained from the previous CAD course.

\section{Comparison to Other Courses}

Many course descriptions and syllabus from Canadian Universities were evaluated during the development of this course but none appear to offer the topics we were planning. Otey et.al.[4]. Published a paper in 2019 that described the evolution of a course at Texas A\&M University that has many aspects in common with the course described here.

The Texas A\&M course also had a focus on improving the CAD skills for follow-on courses, developing skills with industry-standard CAD tools, and included many of the CAD features in their course topics such as corridors, pipe networks, earthworks, etc. The course described by Otey did use Revit in their second version of the course, but Revit was removed in the third version of the course and the course returned its focus to land development projects rather than structural projects, presumably due to difficulties in trying to cover too many different software products in one course.

\section{Conclusion}

This new engineering drawings course developed for civil engineers has benefitted other courses in the program. The surveys conducted to determine student confidence related to the introduction of this course did not indicate significant improvements in student confidence. Further study is warranted to determine the impact of the course introduction on follow-on 
courses in the program. This study will examine the drawings produced by students in a followon course to determine if there are differences in levels of detail, drawing quality, and use of analysis tools.

\section{References}

[1] “AutoCAD For Mac \& Windows | CAD Software | Autodesk." [Online]. Available: https://www.autodesk.ca/en/products/autocad/overview. [Accessed: 02-Feb-2020].

[2] "Skills Competences Canada." [Online]. Available: https://www.skillscompetencescanada.com/en/. [Accessed: 03-Feb-2020].

[3] B.J. Schmid, "Student Support, Confidence, Workload, and Video Resources in a New Civil Engineering Graphics Course," in ASEE Annual Conference and Exposition, Conference Proceedings, 2020.

[4] J. M. (Texas A. U. Otey, J. D. (Purdue U. Camba, and N. (Texas A. U. Danney, "Rethinking Computer-Aided Design in the Civil Engineering Curriculum : Impact and Lessons Learned Rethinking Computer-Aided Design in the Civil Engineering Curriculum : Impact and Lessons Learned," in ASEE 126th Annual Conference and Exposition, Conference Proceedings, 2019. 